\title{
A GÊNESE DA SEMIDIVINDADE DO INTÉRPRETE DE SAMBAS-ENREDO: A PARRESÍA DA VOZ
}

\author{
Luciano C. do Nascimento ${ }^{1}$ (Min. Defesa/Cmdo. Ex.)
}

\begin{abstract}
Resumo: O presente trabalho propõe demonstrar que uma das causas da celebridade do intérprete de sambas-enredo é a parresía de sua voz. Para alcançar tal objetivo, analisa-se uma performance bastante peculiar de um dos mais famosos desses cantores. $\mathrm{O}$ aporte teórico é composto por alguns estudos de Michel Foucault acerca de características do discurso verdadeiro, bem como por incursões de Adriana Cavarero nas searas da ontologia e da semiologia da voz. O resultado é um atestado inconteste da centralidade da voz na constituição da subjetividade.
\end{abstract}

Palavras-chave: discurso; voz; parresía; intérprete de sambas-enredo.

\section{Primeiras palavras}

A exemplo do que outrora aconteceu aos virtuose do canto lírico, atualmente o intérprete de sambas-enredo é tido, no ambiente sociocultural em que atua, como uma espécie de semideus (VALENTE, 2003; NASCIMENTO, 2011). Não são pouco visíveis os indícios que poderiam sugerir essa hipótese; vão desde distinção conferida pelo uso de uma indumentária diferenciada da dos demais integrantes da escola durante sua exibição na passarela, passam pela notoriedade que alguns desses cantores alcançam (sempre hipertrofiada pela exposição midiática em tempos de carnaval) e chegam mesmo a consubstanciar-se no dinheiro e no poder advindos do óbvio e necessário acesso que os intérpretes têm ao microfone das escolas, objeto que circunstancialmente os alça à condição de "porta-vozes do samba" em escala planetária.

Entretanto, este artigo não pretende falar das idiossincrasias relativas a esses cantores, mas, sim, apontar uma das causas mais nucleares de toda essa celebridade. Em resumo, meu principal objetivo neste trabalho é demonstrar teoricamente, mas tomando por base a observação de um caso bastante emblemático, que a origem da semidivindade desses intérpretes está intimamente ligada à legitimidade, à autenticidade, à parrésia (FOUCAULT, 2011) de suas vozes.

Para alcançar esse objetivo, articulo pressupostos discursivos e filosóficos, principalmente sob a égide das perspectivas analíticas de Adriana Cavarero e de Michel Foucault, mas também seguindo passos mais longevos -

1 Doutorando em Literaturas no Programa de Pós-graduação em Literatura da Universidade Federal de Santa Catarina. E-mail: lucprof@globo.com 
de Nietzsche, Aristóteles e Platão. A fundamentação teórica se completa com o recurso às reflexões de alguns pesquisadores brasileiros, como Heloísa Valente e Pedro de Souza, que também têm se dedicado ao estudo da temática da voz num viés ontológico e discursivo.

Ao fim e ao cabo, espero tornar evidente que o intérprete de sambas-enredo, quando em performance, é um parresiasta: há em sua atuação uma constante atualização da aleturgia ${ }^{2}$ (FOUCAULT, 2011) que o faz dignatário da confiança daqueles que devem acompanhar seu canto e de fato o fazem. Esse acompanhamento é um fator indispensável ao sucesso daquele cantor hoje em dia, dados os critérios de julgamento do desfile das agremiações carnavalescas - em particular o denominado "harmonia", que avalia, em síntese, o soar em uníssono das vozes do intérprete oficial, dos componentes da escola, perfeitamente balizados pelo ritmo ditado pela bateria.

\section{Um tanto de teoria}

Foucault dedica seu curso $A$ coragem da verdade (2011) a dar continuidade à discussão sobre o tema da verdade porque, em suas próprias palavras introdutórias à aula de $1^{\circ}$ de fevereiro de 1984, "é interessante e importante analisar, no que elas podem ter de específico, as estruturas próprias dos diferentes discursos que se propõem e são recebidos como verdadeiros" (Ibid., p. 4).

$\mathrm{Na}$ esteira dessa busca, Foucault retoma o método de releitura de textos da Antiguidade Clássica, já empregado no seu curso anterior, O governo de si e dos outros $(2010)^{3}$. Nesse seminário, o filósofo havia iniciado o estudo mais sistemático do conceito de parresía, o ser sincero, o falar francamente, o "dizer-a-verdade", e começara a descrever as diferentes nuances pelas quais "o sujeito, dizendo a verdade, se manifest $a^{4}$, e com isso quero dizer: representa a si mesmo e é reconhecido pelos outros como dizendo a verdade" (2011, p. 4). Da leitura conjunta desses que são os dois últimos cursos ministrados por Michel Foucault no Collége de France, é possível apontar as características principais do discurso parresiástico. Em primeiro lugar, a relação necessária entre o conteúdo dito e o pensamento de quem o diz. É imprescindível que aquele que fala esteja, de fato, expressando sua mais íntima crença, fator

\footnotetext{
2 "Aleturgia" é "a produção da verdade" (FOUCAULT, 2011, p. 4).

${ }^{3}$ Neste trabalho pretendo utilizar reflexões foucaultianas presentes ora num, ora noutro seminário, às vezes em ambos. Os dois cursos, publicados em livros diferentes no Brasil, representam um continum; são, grosso modo, o desenvolver-se de uma mesma pesquisa. Logo, caberá às referências que apresento no corpo deste trabalho apontar quando uma passagem puder ser mais facilmente identificada num ou noutro livro já citados.

${ }^{4}$ Grifos do autor.
} 
primordial na diferenciação entre o parresiasta e o retor (FOUCAULT, 2011, p. 12).

Em segundo lugar, a assimetria. Não há uma relação igualitária de forças. Ora é o mais fraco, que se insurge contra o mais forte a fim de lhe apontar as injustiças, ora é o mais forte, que precisa impor a sua palavra para demonstrar sua condição de mais habilitado a governar.

A consequência advinda do constante risco que a assimetria inerente à parresía engendra é o imperativo da coragem. É preciso coragem para assumir os riscos de que o outro - seja ele o mais forte ou o mais fraco, conforme o caso - não reconheça a fala que se lhe endereça como uma fala verdadeira, e de que o vínculo previamente existente entre os interlocutores se rompa (Ibid.).

Outra característica do discurso parresiástico é maneira como ele se institui. É sempre um jogo, uma encenação em que os papéis devem estar bem definidos: cabe ao parresiasta a coragem e o discernimento para "dizer-averdade", e cabe aos seus interlocutores a boa disposição para ouvi-lo. Diz Foucault (2011, p. 13):

[...] é assim que se estabelecerá o verdadeiro jogo da parresía, a partir dessa espécie de pacto que faz que, se o parresiasta mostra sua coragem dizendo a verdade contra tudo e contra todos, aquele a que essa parresía é endereçada deverá mostrar sua grandeza de alma aceitando que lhe digam a verdade. [...]

A parresía é, portanto, em duas palavras, a coragem da verdade naquele que fala e assume o risco de dizer, a despeito de tudo, toda a verdade que pensa, mas é também a coragem do interlocutor que aceita receber como verdadeira a verdade ferina que ouve.

E é precisamente esse jogo parresiástico que se encena no diálogo platônico Laques, analisado por Foucault (2011). Nele, Sócrates convida Laques e Nícias a participar de um jogo no qual, como o assunto era a competência para ensinar, seria julgada a competência mesma desses dois personagens no tocante ao assunto. Ou seja, para falar sobre um tema, é necessário, segundo Sócrates faz ver, demonstrar-se prévia e realmente apto a dissertar sobre ele, é mister dar provas de que dado ponto-de-vista não é índice de leviandade, mas de "conhecimento de causa", por assim dizer. "Vai se pedir e quase fazer pressão sobre eles [Nícias e Laques] para que aceitem um jogo no qual responderão a questões. Vão ser interrogados sobre o que os torna competentes para falar dessa questão técnica [...]" (Ibid., p. 120).

Pode-se concluir, então, que a visão socrática/platônica defende a necessidade da prova como instrumento de chancela do discurso que se vai fazer, da opinião que se vai emitir. Tudo aquilo que Nícias e Laques disserem só será aceito como verdadeiro se antes eles comprovarem a legitimidade e a credibilidade de suas ideias, por meio da invocação do valor de seus mestres, 
ou pela declinação dos méritos de seus discípulos (o produto de seu trabalho, suas obras, enfim).

Algo muito semelhante ocorre com o intérprete de sambas-enredo. Ele também precisa comprovar sua competência para ocupar aquela posição. Quando em situação de performance, o "puxador" (expressão demonizada por Jamelão, o mais célebre dos cantores de sambas-enredo) é alguém em quem cada componente da escola precisa confiar. É dele a voz guia que, metonimicamente, se torna a voz da própria agremiação. Assim, a legitimidade de sua condição de porta-voz não pode estar em dúvida. Para tal, ele precisa dar constantes demonstrações de habilidade, técnica e potência vocais que lhes são próprias. Isso é parte do ritual aletúrgico em que, por força, está inserido. Em suma, o intérprete deve mostrar que tem um diferencial, que não é um cantor qualquer, que sua voz pode e deve ser seguida por todos. É uma questão de credibilidade.

Os gregos chamavam de ethos a imagem (discursiva) de credibilidade, de confiabilidade que um orador devia assumir diante de sua audiência a fim de convencê-la. Aristóteles (2005), em sua Arte retórica, afirma que o ethos é uma "prova"; é uma construção discursiva deliberada, a partir de um conjunto de procedimentos/comportamentos, visando à persuasão ${ }^{5}$. Foucault (2011, p. 25), por sua vez, defende categoricamente a relação entre parresía e ethos: este é "o domínio" daquela. Assim, para o filósofo francês, o parresiasta é aquele em cuja fala se confia, porque nela a verdade, mais do que apenas dita, é encenada - por meio de um modus vivendi, até, no caso dos cínicos (id., p 145).

Assim, assumindo que, por extensão, em qualquer performance artística também há um grau elevado de argumentatividade ${ }^{6}$, conclui-se que o intérprete de sambas-enredo, em meio ao verdadeiro panótico pós-moderno no qual se transformou o sambódromo do Rio de Janeiro durante os desfiles de carnaval do Grupo Especial das escolas de samba, está também argumentando, está tentando persuadir sua audiência (foliões desfilantes e espectadores) a crer que a sua voz (a do cantor) é a voz da própria escola, sua interpretação é a interpretação da escola, e que, por isso, todos devem unir-se a ela, em coro. Nesse caso, ele terá tanto mais sucesso em seu objetivo, ou seja, obterá tanto mais adesão ao seu canto, quanto mais der provas de que é digno de confiança, quanto mais fizer coincidir sua tese e sua prática.

Assim, de forma análoga ao que se pode depreender do diálogo platônico no que concerne ao poder opinar sobre o saber técnico, apenas uma boa fama não basta ao intérprete de sambas-enredo. Cabe a ele - no afã de merecer (ou manter) a confiança e a adesão de seus guiados - dar demonstrações de seu virtuosismo. Ele precisa provar (do) que é capaz. Acerca

\footnotetext{
${ }^{5}$ Sobre o ethos, ver também Amossy (2005) e Nascimento (2006).

${ }^{6}$ Considerando, no limite, o teor catártico imanente à própria noção de Arte, em sentido lato.
} 
disso, Valente (2003, p. 43) afirma, sobre o artista virtuoso (que também é comparado com um semideus pela autora), que ele deve ser viril e dar provas de virilidade, pois, não raro, seu público está mais interessado nessas façanhas performáticas do que no conteúdo efetivamente evocado pela letra da composição.

Ressalte-se, ainda, que, no caso específico desse tipo de performance (à frente de algo em torno de 4.000 pessoas em êxtase bacante, tendo outros tantos milhões de foliões espectadores, in locco ou pela TV, rádio ou internet), nem um fôlego excelente, nem um timbre peculiar, e nem mesmo uma ampla extensão vocal garantem o sucesso. Aliás, a pouca ocorrência de cantores de outros gêneros musicais à frente de escolas de samba já é um sinal de que ocupar aquela posição demande características específicas.

Parece mesmo claro que, para qualquer cantor profissional, digamos, "convencional", cantar ininterruptamente por, pelo menos, 65 minutos (tempo mínimo regulamentar de desfile de uma agremiação carnavalesca do Grupo Especial do Rio de Janeiro) já seria uma tarefa hercúlea ${ }^{7}$. Mas o principal é que, até chegar a esse ponto, o cantor de que falamos neste texto já deverá ter sido aceito por essa agremiação, já deverá ter "assumido o microfone", no jargão daquele meio.

O caminho até aí é sinuoso e envolve uma sucessão de momentos, às vezes, um tanto íntimos até, mas a maioria deles públicos decerto, em que, passo a passo, o intérprete desse gênero musical vai esculpindo, com a voz, as suas próprias credibilidade e legitimidade (dos dois, tanto dele, em pessoa, quanto de sua voz, per se).

É um desses momentos de coragem, de pôr-se à prova - condição inerente a todo discurso parresiástico (FOUCAULT, 2011) -, que passo a observar a seguir. É mesmo um instante um tanto íntimo, se comparado à exposição em escala planetária a que se submete o cantor de uma escola de samba no desfile oficial. Trata-se de uma performance de Vander Pires (famoso puxador de sambas-enredo, com passagens por grandes agremiações do Rio e de São Paulo) na quadra do GRES Império da Casa Verde, uma grande escola de samba paulista, em 2008.

Antes, porém, de iniciar efetivamente o estudo daquela apresentação, é imprescindível, ainda, antecipar-me ao argumento de quem, não familiarizado com a concepção de voz que norteia minhas observações, se apressará em dizer que pratico pura exegese, e tenciono, de maneira exagerada

\footnotetext{
${ }^{7} \mathrm{Na}$ realidade, são poucos os intérpretes que ainda cantam efetivamente todo o tempo do desfile. É mais comum que, ao longo desse tempo haja um revezamento, e que o intérprete principal por vezes preencha as lacunas de sua voz - na sequência da letra do samba - com o que eles chamam de "cacos", vocalizações que têm algumas funções bem definidas na estrutura daquela performance (cf. NASCIMENTO, 2011).
} 
e tendenciosa, a ligação entre texto e situação comunicativa. Nada seria mais injusto.

Segundo Cavarero (2011, p. 23), ela, a voz, é um sinal indiscutível da unicidade, da individualidade do ser humano, e compõe uma esfera pré-verbal, independente do conteúdo lógico-semântico articulado pelo léxico. Logo, para citar Souza (2009, p. 35), é possível estudar a voz posta em funcionamento "em um campo de discurso em relação ao qual o objetivo não é articular a voz a uma ordem de sentido, mas operar analiticamente sua colocação em abismo".

Visto que esta proposta de trabalho assenta na observação de uma instância pré-verbal, seria incoerente realçar a ligação entre tal instância e o conteúdo linguístico do texto (cantado). Isso não quer dizer, é claro, que aqui seja negado qualquer grau de relação entre o veículo da expressão (a voz) e a matéria expressa (as palavras). Absolutamente. Implica dizer, apenas, que a voz é tomada, neste estudo, como um elemento significativo suprassegmental. Mais: um componente semiótico que atravessa o linguístico (porque vem antes e vai além deste).

O ganho epistemológico da assunção da natureza peculiar desse objeto é obter-se uma perspectiva privilegiada, por estar fundada num traço distintivo, gerador de marcas de unicidade, de individualidade; uma perspectiva, enfim, que realça um valor ontológico cuja função produtora de sentido não escapa à percepção laica mais simplória e cotidiana.

Feito esse esclarecimento, parto para a análise da performance aludida.

\section{"Uma voz 'mais alta' se alevanta"}

Vander Pires é uma unanimidade: é um dos melhores intérpretes de sambas-enredo da atualidade. Desde há muito tempo, na verdade. Seus mais de 15 anos de carreira são cheios de sucesso ${ }^{8}$. Mesmo entre seus pares, são frequentes as referências ao seu talento e à "potência" de sua voz, à beleza de seu timbre. Essa qualidade foi premiada com um Estandarte de Ouro - uma distinção oferecida pelo Jornal O Globo aos destaques do carnaval - em $1997^{9}$. Tamanho sucesso caminha lado a lado com alguns episódios polêmicos na vida profissional do cantor. As passagens por várias escolas do Rio de Janeiro, algumas de São Paulo (e, mais recentemente, até uma agremiação de Porto

\footnotetext{
${ }^{8}$ Dados biográficos e da carreira do cantor disponíveis em:

http://www.sambariocarnaval.com/frames/index.php?sambando=wander. Acesso em: 07.mar.12. ${ }^{9}$ Disponível em:

http://www.academiadosamba.com.br/memoriasamba/estandartedeouro/puxador.htm. Acesso em: 07.mar.12.
} 
Alegre) são, em geral, rápidas; há quem reclame do temperamento (supostamente) forte de Vander...

Num momento de efervescência dessas polêmicas, o cantor foi apresentado na quadra do GRES Império da Casa Verde como o intérprete oficial da escola para o carnaval de $2009^{10}$ (o evento ocorreu em meados de 2008). Ele acabara de ser afastado do GRES Acadêmicos do Grande Rio, segundo consta, por quebra de contrato. Algo parecido já ocorrera na GRES Unidos do Viradouro ${ }^{11}$.

Acompanhado apenas por um violão e um cavaquinho, Vander subiu ao palco e começou a cantar "Sangrando" 12 , sucesso de Gonzaguinha. O inusitado da escolha do gênero musical é um dos componentes a que se deve atentar; o acompanhamento exclusivo de instrumentos de harmonia, num ambiente onde geralmente reina a percussão, é outro fator interessante; e, por fim, a execução, a performance vocal do cantor, stricto sensu.

Quando se vê uma quadra de escola de samba lotada, o que se espera ouvir ali é, sem dúvida, samba. Apelar para esse truísmo parece ainda mais desnecessário se quem aparece em cena é o intérprete oficial da agremiação. Indo mais longe: se se sabe que aquele intérprete está chegando à escola, está sendo apresentado como recente contratação, espera-se, normalmente, que ele cante um samba de enredo famoso (de preferência da própria escola), que busque se entrosar com a bateria, que seja simpático com o público etc..., mas não que fuja ao ritual comum àquele momento.

Vestido de terno branco, sob os holofotes que iluminavam o centro do palco, o cantor se valeu de um recurso cênico, textual, discursivo (comunicativo, lato sensu) bastante produtivo: a quebra de expectativa. Pegou o microfone, e "soltou a voz".

Por ser um puxador já famoso e premiado no Rio de Janeiro, o oficialmente declarado nascedouro do samba (BRASIL, 2007), não é exagero supor que a maioria do público naquele espaço paulistano esperasse que Vander cantasse um dos sambas com que se notabilizara no GRES Mocidade Independente de Padre Miguel (onde fora campeão, inclusive), ou no Salgueiro, escolas tradicionais do carnaval carioca; ou pelo menos uma composição de alguma escola de São Paulo. É improvável que alguém ali esperasse outro gênero musical naquele momento, até pelo fato de poucos

10 Fato que acabou não acontecendo, cf. <http://www.sidneyrezende.com/noticia/12534>. Acesso em: 12.mar.2012.

${ }^{11}$ Conforme reportagens disponíveis em <http://www.sidneyrezende.com/noticia/12290>, $<$ http://www.sidneyrezende.com/noticia/12353>,

$<$ http://www.sidneyrezende.com/noticia/100669>. Todos os links foram acessados em 08.mar.12.

12 Vídeo disponível em <http://www.youtube.com/watch?v=wImbOSDwvV0>. Acesso em: 07.mar.12. 
puxadores se arriscarem em outros gêneros ao vivo, menos ainda diante de público tão numeroso.

Ao dispensar os instrumentos de percussão que normalmente fazem a introdução para o canto nessas situações e ao optar por uma melodia lânguida (interrompida por uma breve pausa), o recém-chegado intérprete oficial da escola criou um surpreendente ambiente de silêncio, suscitou um tempo de suspense que poderia ser caracterizado como de "ansiosa escuta contemplativa". Essa postura das pessoas fez com que a voz do cantor soasse praticamente sozinha no primeiro verso daquela conhecida canção. O resultado foram os efusivos aplausos já no início da performance.

A opção por um acompanhamento minimalista (apenas dois instrumentos de corda) trouxe ainda outro componente relevante para esse quadro inicial: o cavaquinho, apenas executando contrapontos, e o violão, harpejando caminhos harmônicos de modo bastante comedido, faziam apenas uma suave alusão à melodia, arranjo que colocou mais ainda em primeiro plano a voz do cantor, que a sustentava (à própria melodia).

Sobre esse tipo de sugestão sonora, diz Nietzsche (2005, p.12): “a música de Apolo é a arquitetura dos sons, acrescente-se ainda, dos sons apenas aludidos, tais como são próprios da cítara"13". Por outro lado, "o poder comovedor do som e o mundo incomparável da harmonia" são, para o filósofo, "o elemento que perfaz o caráter da música dionisíaca"14 (Id.).

É interessante que Nietzsche se valha, em seu comentário, de uma comparação com outro instrumento de cordas, a cítara, para sinalizar que tipo de sons musicais são relativos a Apolo. Sim, porque, se a cítara (ou a lira) do deus Sol encanta e enleva e se uma voz se eleva frente a ela, isso significa que essa não é uma voz qualquer, mas, sim, algo também divinal, também encantatório.

Como a de Orpheu, por exemplo, filho do Deus de Delfos, e cuja música parava as águas dos rios, amansava as feras e amolecia os rochedos. Algo comparável, por sua vez, a calar uma quadra de escola de samba cheia de foliões ansiosos pelo frisson da bateria - que, aliás, também aguardava silenciosa o fim da performance do cantor, para saudá-los (a ele e à sua voz). Posta em

${ }^{13}$ Grifos nossos.
${ }^{14}$ Segundo o filósofo alemão (2005, p. 9), a arte dionisíaca é a que se caracteriza pela embriaguez,
pela entrega - quase - irracional ao prazer e à fruição. Como a noção de harmonia, no universo
semântico-discursivo do carnaval das escolas de samba, está relacionada com a participação efetiva
dos componentes da escola no canto, em uníssono, ritmado pela pulsação da bateria, guiado pela
voz do intérprete oficial, não parece absurdo inferir que, no desfile carnavalesco, há um canto
dionisíaco, embriagado e frenético, inclusive porque ligado a instrumentos de percussão (que
marcam, definem o ritmo), e não aos de corda (que apenas sugerem o som) como de praxe na
calma música apolínea. 
evidência pelo acompanhamento apolíneo, foi ela, a voz de Vander, que hipnotizou a todos ${ }^{15}$.

É possível afirmar esse fato também por conta da maneira como o cantor explorou sua própria capacidade vocal. A comparação com uma interpretação do autor da música, Gonzaguinha, na década de $80^{16}$, é bastante elucidativa. Vander canta três tons acima daquele em que estava Gonzaguinha; o andamento é bem mais lento na versão mais recente (o que provoca um alongamento das sílabas, momentos em que o sambista sustenta notas agudas e graves mais duradouras); na execução mais antiga, o mesmo tom se mantém do começo ao fim, enquanto, na outra, o intérprete sinaliza para os músicos aumentarem meio tom, e todo o refrão é repetido numa tonalidade ainda mais aguda; a sílaba final da letra é cantada por Gonzaguinha com uma nota aguda, dando continuidade à harmonia de todo o verso, ao passo que Vander quebra a linha harmônica fazendo soar um "amar" grave e intimista, uma nota "de peito".

"De peito" porque é essa a expressão com que se nomeia a execução desse tipo de nota, por conta de seu ponto de ressonância. Mas não posso me furtar a explorar uma interessante ambiguidade possível, porque valer-se daquele recurso é parte da corajosa estratégia do cantor; é uma atitude "de peito". Não se pode negligenciar o fato de que ele estava chegando a uma nova escola. Em qualquer ambiente profissional, por mais ortodoxo que seja, é comum observar funcionários recém-contratados buscando "mostrar serviço". É uma atitude perfeitamente legítima.

Assim, Vander Pires se arrisca muito numa interpretação ousada, personalíssima, em que dá provas de suas técnica, timbre, e, principalmente, extensão vocais. Diante da audição e do olhar atentos de alguns milhares de pessoas (e grande parte delas decerto estava ali principalmente para vê-lo cantar), no calor de todas as polêmicas pessoais e profissionais em que havia se envolvido no Rio de Janeiro, ele confirma seu ethos prévio (MAINGUENEAU, 2005; NASCIMENTO, 2006) de grande intérprete, ou seja, demonstra qualidade, transmite segurança e, a julgar pela reação do público, ratifica a confiabilidade e a credibilidade de sua voz.

Estabeleceu-se, assim, o jogo parresiástico. O cantor estava ali como quem dissesse: "esta é a voz da escola agora"; o público, que acompanhara a performance e a aplaudira, estava convencido de que aquilo era verdade, de que havia naquela vOz traços verdadeiramente diferenciados (e diferenciadores) de timbre, extensão, segurança..., valores desejáveis para a boa constituição "orgânica" da escola.

15 Outra analogia possível é com a voz do canto sedutor das sereias, a que Cavarero (2011, p. 129) faz alusão... Essa pequena digressão merecerá ser desenvolvida num trabalho de maior fôlego.

${ }^{16}$ Disponível em: < http://www.youtube.com/watch?v=5Iz7HkbLXqM>. Acesso em: 08.mar.12. 
É interessante notar, também, que corrobora a existência de um pacto parresiástico o fato de que, como Foucault afirma (2011, p. 97), "parresía não é exercício de poder". Íon - personagem central que dá nome a uma peça de Eurípedes analisada pelo filósofo francês (FOUCAULT, 2010) - quer "se sentar na primeira fileira da polis", mas para isso não adianta a paternidade tal qual ela se lhe apresenta. De maneira análoga, para que Vander conquistasse a confiança da comunidade e o respectivo e necessário grau de adesão à sua voz, não bastava ser apresentado pela diretoria como o novo intérprete oficial. Era indispensável dar provas de sua competência (como Sócrates propõe a Laques e Nícias), era preciso persuadir, pelo ethos. Ou, em síntese, ele precisava ter reconhecida sua parresía.

Para endossar ainda mais essa análise, talvez seja útil evocar uma marca estritamente linguística da intencionalidade que aqui atribuo ao cantor. Afinal, como já afirmei antes, a voz se inscreve antes e para além do linguístico, segundo a vertente teórica aqui desenvolvida, mas isso não anula a possibilidade metodológica de consideração da interpenetração entre os dois campos. Já no final da canção, Vander assume marcada e explicitamente a função-sujeito do enunciado que canta; ele inclui, incidentalmente, entre os versos da letra, o vocativo "Casa", por meio do qual se refere de maneira metonímica ao público - valendo-se de uma abreviação do nome da agremiação (Império da Casa Verde).

Nesse momento, assumindo a $1^{a}$ pessoa (por ser quem toma o turno de fala e se dirige à $2^{\mathrm{a}}$, a quem se dirige o vocativo), Vander demonstra ter consciência de que o conteúdo linguístico-textual daquela canção se relaciona intimamente com o projeto de persuasão em andamento, no afã de merecer a confiança e a admiração dos integrantes da escola (e dela própria, invertendo-se a orientação da metonímia). É cúmplice a assunção de: "quando $e$ u soltar a minha voz/(que pede, Casa, pede) por favor entenda/é apenas o meu jeito de dizer/o que é amar" [grifos meus]. Ressalte-se ainda que, estritamente do ponto de vista sintático-semântico, quem "pede" é a "voz" de Vander.

A performance vocal de Vander Pires é, por fim, a clara exemplificação de outra definição de parresía que Foucault apresenta (FOUCAULT, 2011, p. 97): "uma espécie de palavra mais alta, mais alta que o estatuto de cidadão, diferente do exercício puro e simples do poder". E arremata (Ibid., p. 98):

[...] é uma palavra que dá liberdade a outras palavras, e que dá liberdade aos que têm que obedecer, que lhes dá a liberdade, pelo menos na medida em que só obedecerão se puderem ser persuadidos.

[...] uma palavra que persuada os que são comandados e que num jogo agonístico dê liberdade aos outros que também querem comandar é, ao meu ver, o que constitui a parresía. 
Dando tamanha demonstração de poder vocal, Vander mostra que não é um folião qualquer, nem um qualquer cantor. Ele persuade a todos sobre seu valor, sobre a legitimidade de sua condição de intérprete oficial da escola e sobre a necessidade de os demais componentes da agremiação o seguirem. $\mathrm{O}$ que significa dizer, em se tratando de uma agremiação carnavalesca, que é ele o responsável por conduzir a todos os integrantes da escola à liberdade, à quebra das regras, à subversão, à euforia, à alegria que caracterizam o tempo-espaço carnavalizado (BAKHTIN, 1999).

\section{Por fim}

A proposta inicial deste artigo era demonstrar uma das causas da (quase) semidivindade dos intérpretes de sambas-enredo: a parresía das vozes desses cantores. Esse conceito - o de parresía - foi rapidamente apresentado e explicitado à luz das palavras de Michel Foucault (2010; 2011); a concepção de voz aqui adotada foi a mesma compartilhada por Adriana Cavarero (2011), Pedro de Souza (2009) e Heloísa Valente (2003).

Valendo-me das peculiaridades de uma performance de Vander Pires famoso intérprete, com passagens por várias grandes escolas de samba do Rio de Janeiro e de São Paulo - procurei apontar traços daquilo que se pode entender como um jogo parresiástico encenado pelo cantor no momentochave de sua chegada a uma nova agremiação, momento de fundar os alicerces de sua credibilidade como intérprete (e funcionário).

Ao fim, espero ter, mesmo se tangencialmente, despertado a atenção do leitor para a observação de um fator que é o principal pressuposto deste trabalho: o valor ontológico da voz na constituição da nossa subjetividade, lato sensu. O tema é produtivo e comporta abordagens as mais variadas como a aqui desenvolvida. Se mais não faça, que ela ao menos convide a "soltar a voz"...

\section{REFERÊNCIAS}

AMOSSY, R (org.). Imagens de si no discurso - a construção do ethos. São Paulo: Contexto, 2005.

ARISTÓTELES. Arte Retórica e Arte Poética. Rio de Janeiro: Ediouro, 17. ed., 2005.

BAKHTIN, M. A cultura popular na Idade Média e no Renascimento: o contexto de François Rabelais. São Paulo: Hucitec/ UnB 1999.

BRASIL, Min. Cultura. Matrizes do samba. Brasília: IPHAN,2007. Disponível em: $<$ http://portal.iphan.gov.br/portal/baixaFcdAnexo.do?id=940>. Acesso em: 31.jan.2012. 
CAVARERO, A. Vozes plurais - filosofia da expressão vocal. Belo Horizonte: UFMG, 2011.

FOUCAULT, M. O governo de si e dos outros. São Paulo, Martins Fontes, 2010.

. A coragem da verdade. São Paulo: Martins Fontes, 2011.

MAINGUENEAU. D. Ethos, cenografia, incorporação. In: AMOSSY, Ruth (org.). Imagens de si no discurso, a construção do ethos. São Paulo: Contexto, 2005.

NASCIMENTO, L. C. do. A performance vocal dos intérpretes de sambasenredo das escolas de samba do Rio de Janeiro. In: Revisa Boitatá - Revista do GT de Literatura Oral e Popular da ANPOLL. Disponível em <http://www.uel.br/revistas/boitata/volume-12-2011/B1214.pdf>. Acesso em: 14.mar.2012.

A materialidade linguística da construção do ethos - uma perspectiva discursiva e cognitivista. Dissertação de Mestrado. Rio de Janeiro, UFRJ: $2006 . \quad$ Disponível em $<$ http://www.letras.ufrj.br/posverna/mestrado/NascimentoLC.pdf $>$. Acesso em: 14.mar.2012.

NIETZSCHE, F. A visão dionisíaca do mundo. São Paulo: Martins Fontes, 2005.

PLATÃO. Laques. Disponível em $<$ http://search.4shared.com/postDownload/OyqzvZqK/Plato_Laques.html >. Acesso em: 14.mar.2012.

SOUZA. P. de. Michel Foucault: o trajeto da voz na ordem do discurso. Campinas: RG, 2009.

VALENTE, H. As vozes da canção na mídia. São Paulo: Via Lettera/ Fapesp, 2003. 